\title{
Editorial comemorativo ao volume 100 da Iheringia Série Zoologia
}

No final do primeiro semestre de 2010 - ano internacional da Biodiversidade e também do $55^{\circ}$ aniversário do Museu de Ciências Naturais da Fundação Zoobotânica do Rio Grande do Sul - surgiu a idéia da publicação de um número comemorativo ao volume de número 100 da Iheringia Série Zoologia (ISZ), que ora apresentamos com muito orgulho e satisfação.

Ainda que dispondo de um tempo relativamente curto para a realização de tal tarefa, a Comissão Editorial da ISZe colaboradores aceitaram este honroso desafio, convictos de que os benefícios da proposta seriam compensadores. Especialistas de diferentes instituições e áreas do conhecimento zoológico foram então convidados a submeter artigos inéditos de cunho revisório para publicação na edição comemorativa. Os convites consideraram o envolvimento histórico dos autores com a revista e/ou a sua condição de pesquisadores expoentes em sua linha de pesquisa ou grupo zoológico de especialidade. A proposta teve como escopo a produção de artigos com enfoque amplo e que, de alguma forma, permitissem uma avaliação do "estado da arte" das pesquisas sobre determinados grupos zoológicos no Rio Grande do Sul (ou em uma região ainda mais abrangente) sob diversos enfoques. Nesse contexto, algumas normas da ISZ foram excepcionalmente flexibilizadas, a exemplo do número máximo de laudas para submissão e a possibilidade de publicação de notas expandidas.

Embora não tenha sido possível contar com a contribuição de todos os pesquisadores inicialmente convidados, os manuscritos recebidos representam uma contribuição inestimável ao conhecimento sobre a diversidade da fauna gaúcha e nacional, marcando de forma brilhante a passagem dessa importante conquista da ISZ, que é a publicação do seu centésimo volume. Em acréscimo, além dos artigos da seção comemorativa, o número 4 do volume 100 também traz trabalhos inéditos de tramitação regular, em conformidade com o escopo tradicional da revista.

A seção comemorativa inicia com um artigo de autoria da própria Comissão Editorial, o qual apresenta um breve histórico da ISZ e sintetiza o impacto da revista no conhecimento da fauna neotropical recente, seguindo-se então os artigos de autores convidados.

OPrograma Macacos Urbanos apresenta pela primeira vez uma abordagem transdiciplinar para a conservação do bugio-ruivo na região da capital gaúcha. $\mathrm{O}$ programa vem pesquisando a distribuição de Alouatta guariba clamitans e avaliando as ameaças às populações na região metropolitana de Porto Alegre desde 1993, além de desenvolver e implementar estratégias de conservação para a espécie. No artigo, os resultados sinergéticos das diferentes abordagens do projeto e sua relação com a primatologia no sul do Brasil são apresentados, sugerindo que trabalhos desenvolvidos coletivamente e a atuação em múltiplas frentes de trabalho são essenciais para se atingir metas conservacionistas.

A seguir, Clóvis S. Bujes comenta a diversidade de quelônios continentais do Rio Grande do Sul através de uma compilação de dados (já publicados ou inéditos) sobre sua biologia, taxonomia e estado de conservação.

Jairo L. Cândido e colaboradores redefinem Dosilia, gênero de poríferos de água doce, incluindo chave para identificação das espécies e redescrições.

Augusto Ferrari e colaboradores descrevem uma aplicação da análise de endemismos nos padrões de distribuição de 222 espécies de 14 gêneros de pentatomídeos nos diferentes biomas brasileiros. $\mathrm{O}$ artigo evidencia que maximizar a acuidade das unidades empregadas em análises biogeográficas é fundamental para melhor embasar hipóteses sobre a evolução desta família.

João C. Nabout e colaboradores fazem uma revisão da literatura acerca das tendências e perspectivas das pesquisas sobre o gênero Uca entre os anos de 1991 e 2007. Atualmente são conhecidas 97 espécies nesse gênero de crustáceos, mas até o presente inexistia um trabalho de síntese das informações científicas sobre o grupo.

Marco A. Azevedo explora as relações existentes entre a biologia reprodutiva, tamanho corporal e relações filogenéticas dos caracídeos, contribuindo para a compreensão da evolução das estratégias reprodutivas nessa família de peixes.

Erica H. Buckup e colaboradores apresentam a lista das espécies de aranhas do Rio Grande do Sul (808 espécies de 51 famílias), incluindo para cada táxon localidade-tipo, ocorrência e respectivas bibliografias. A lista consiste numa síntese do conhecimento taxonômico das espécies de aranhas descritas ou registradas para o Rio Grande do Sul nos últimos 130 anos, com base na revisão de 439 trabalhos científicos e do acervo do Museu de Ciências Naturais/FZBRS.

Glayson A. Bencke e colaboradores revisam e atualizam a lista das aves do estado 32 anos após a ISZ ter publicado a primeira lista, de autoria de William Belton. Nessa revisão, são propostas ações práticas para aperfeiçoar o processo de revisão da lista estadual no futuro. Seguramente, esse trabalho minucioso servirá de subsídio para especialistas, órgãos governamentais e também para os apreciadores da observação de aves na natureza.

No contexto das notas expandidas, inserem-se também algumas notas sobre aves, incluindo a descrição de um novo morfo de coloração e novos registros de aves marinhas/costeiras com implicações importantes para o conhecimento da distribuição, status de ocorrência, biogeografia e conservação das espécies enfocadas.

Em nome da atual Comissão Editorial, gostaria de parabenizar às muitas pessoas que, ao longo desses mais de 50 anos de existência, contribuíram para que a ISZ chegasse até aqui. Também agradecemos aos funcionários e equipe diretiva do Museu de Ciências Naturais e da Fundação Zoobotânica do Rio Grande do Sul, aos autores, aos consultores, ao CNPq, a CAPES e ao SciELO, pelo constante e relevante apoio recebido.

Daniela Sanfelice 